\title{
RESPONSABILIDADE AMBIENTAL, CUSTO DE CAPITAL, RISCO E ENDIVIDAMENTO
}

\author{
Jessica Prado Martins ${ }^{1}$ \\ Danilo Soares Monte-mor ${ }^{2}$ \\ Silvania Neris $\mathrm{Nossa}^{3}$ \\ Valcemiro Nossa ${ }^{4}$
}

Resumo: O presente estudo teve por objetivo verificar o efeito da sinalização ambiental na estrutura de capital. A certificação ISO 14001 foi empregada como proxy de sinalização para o mercado de empresas que são comprometidas com sustentabilidade ambiental. Os dados coletados se referem ao período de 1995 a 2016, sendo a amostra final de 2365 firmas/ano. Utilizou-se um modelo "difference in difference" com efeito fixo para empresa, com o intuito de se estimar o efeito da obtenção da certificação na estrutura de capital, risco e nível de endividamento mediante a comparação de empresas que receberam a respectiva certificação do Sistema de Gestão Ambiental com empresas que não possuem tal certificação. Um Propensity Score Matching também foi efetuado para se mitigar um possível viés de auto-seleção. Os resultados sugerem que embora a adoção de práticas de gerenciamento exigidas pelos padrões ISO14001 não reduza em média o risco sistêmico das empresas, percebe-se alteração na estrutura de capital das empresas certificadas a partir da redução do custo de capital de terceiros e aumento da proporção da dívida de longo prazo.

Palavras-chave: Certificação. Sinalização. Custo de capital. Risco. Dívida.

jejepmartins@hotmail.com - Fucape Business School - Vitória-ES, Brasil. http://orcid.org/0000-0003-0678-8700

2 danilo@fucape.br - Fucape Business School - Vitória-ES, Brasil. http://orcid.org/0000-0002-5677-5804

${ }^{3}$ silvania@fucape.br - Fucape Business School - Vitória-ES, Brasil. http://orcid.org/0000-0001-8087-109X

${ }^{4}$ valcemiro@fucape.br - Fucape Business School - Vitória-ES, Brasil. http://orcid.org/0000-0001-8091-2744

- DOI: http://dx.doi.org/10.14392/asaa.2019120207

- Artigo submetido em: 08/08/2018. Revisões requeridas em: 24/04/2019. Aceito em: 25/08/2019. 


\title{
ENVIRONMENTAL RESPONSIBILITY, COST OF CAPITAL, RISK AND DEBT
}

\begin{abstract}
The present study aimed to verify the effect of environmental signaling on the capital structure. The ISO 14001 certification was used as a signaling proxy for the market of companies that are committed to environmental sustainability. The data collected refer to the period from 1995 to 2016, and the final sample formed by 2365 firm/year. A "difference in difference" model with fixed effect was used to estimate the effect of obtaining certification in the capital structure, risk and level of indebtedness by comparing companies that received the respective ISO14001 certification with companies that do not have such certification. A Propensity Score Matching was also implemented to mitigate a possible self-selection bias. The results suggest that although the adoption of management practices required by the ISO14001 standards does not reduce on average the systemic risk of companies, it is possible to notice a change in the capital structure of certified companies by reducing the cost of debt and increasing the proportion of long-term debt.
\end{abstract}

Palavras-chave: Certification. Signaling. Cost of capital. Risk, Debt. 


\section{INTRODUÇÃO}

A sinalização de Responsabilidade Social Ambiental (RSA) vem assumindo um papel que pode auxiliar a empresa no diálogo com os investidores e com a sociedade (Lock \& Seele, 2015), fornecendo sinais de transparência que aumentam a reputação e melhoram o perfil social dos gerentes criando valor para seus acionistas e reduzindo riscos (Ahmadi \& Bouri, 2017). A partir do momento em que a responsabilidade ambiental é percebida por exercer influência sobre o desempenho corporativo, muitas empresas podem estar voltando seus olhares para suas atitudes em prol do meio ambiente como um fator estratégico (Lock \& Seele; 2015; Testa \& D’Amato, 2017).

Entretanto, os trabalhos realizados nessa esfera indicam, além das questões ambientais, as questões financeiras. Por exemplo, o estudo de Teixeira, Nossa, Funchal (2011), mostra que o Índice de Sustentabilidade Empresarial (ISE), exerce influência sobre as estruturas de capital, inclusive encontrando indícios de melhor relacionamento com stakeholders em especial credores e acionistas quando aderem ao ISE (Teixeira et al., 2011).

Por um lado, a implementação de um sistema de gestão ambiental nos padrões internacionais (ISO) exige das empresas investimento em mudanças administrativas, organizacionais, deficiências regulatórias e até de infra-estrutura nacionais, e neste contexto a certificação pode afetar os custos (Christmann, 2000; Matuszak-Flejszman, 2009; Massoud, Fayad, Kamled, \& El-Fadel, 2010). Por outro lado, Song, Zhao, \& Zeng (2017) afirmam que há a redução dos custos por meio da implementação do Sistema de Gestão ambiental (SGA) ISO 14001 devido à reutilização de matérias-primas e energia. Este contexto pode melhorar a eficiência da produção, possibilita a redução dos vazamentos e poluição, reduzindo assim os custos de regulamentação governamentais em restauração ambiental, remoção de poluição no meio externo e redução de riscos (Lock \& Seele; 2015; Ahmadi \& Bouri, 2017; Testa \& D’Amato, 2017, Song, Zhao, \& Zeng, 2017).

Diante da ambiguidade do cenário apresentado surge um contexto de pesquisa, pois o mercado pode interprestar a certificação ambiental como um sinal positivo se acreditar que a certificação ISO 14001 reduz os custos, mas pode ser percebido pelo mercado como um sinal negativo se a certificação aumentar os custos. E neste sentido, ao analisar 214 empresas nos EUA, Erragragui (2017) encontrou evidências empíricas de que as preocupações socioambientais aumentam o custo da dívida das empresas. Diante dos resultados encontrados surge uma lacuna de pesquisa, uma vez que não foi encontrado do mercado brasileiro um estudo. Diante disso, o objetivo desse artigo é verificar especificamente o efeito da sinalização ambiental empresarial no custo da dívida e na estrutura de capital das empresas brasileiras listadas na B3.

O financiamento da dívida é uma fonte externa de recursos por meio do qual empresas podem realizar investimentos (Erragragui, 2017). As informações divulgadas pela empresa podem interferir em diversas decisões dos stakeholders. Assim, torna-se relevante investigar os motivos e possíveis consequências da sinalização, divulgação e comprometimento das iniciativas de responsabilidade ambiental das empresas (Erragragui, 2017). No contexto deste estudo, a certificação ISO 14001 (ambiental) será empregada como proxy de sinalização para o mercado de empresas que têm certificação. O propósito é verificar se o custo da dívida e endividamento das empresas com certificação que sinalizaria sustentabilidade, se diferenciam respectivamente daquelas empresas sem a certificação. O contexto analisado é fundamentado no fato de que uma vez certificadas as empresas são auditadas periodicamente a fim de que se possa garantir o 
cumprimento dos requisitos da norma ISO 14001 e no caso de descumprimento das normas a empresa pode perder a certificação (Dogui, Boiral, \& Heras-Saizarbitoria, 2014).

Por um lado, a literatura registra que há o aumento de custos na implementação da certificação (Christmann, 2000; Matuszak-Flejszman, 2009; Massoud et al., 2010, Martín-de Castro, Amores-Salvadó, \& Navas-López, 2015). Mas, por outro lado alguns comportamentos de responsabilidade social ambiental podem melhorar os fluxos de caixa futuros de uma empresa (Mackey, Mackey, \& Barney, 2007). Tais autores argumentam ainda que empresas certificadas podem se diferenciar das demais empresas concorrentes no mercado quando comparados os produtos. Outro contexto positivo para a empresa pode ser a redução de custos ligados à gestão de desastres ambientais impostos por um regulador (Weber, 2012). Neste sentido Spicer (1978) defendia que a certificação pode ajudar na redução de multas impostas pelo governo.

A Responsabilidade Social Corporativa (RSC) que engloba a RSA possui uma característica de "atribuição de valor" que outros investimentos estratégicos não possuem (Vasi \& King, 2012). Por meio da RSA, as empresas estabelecem relações mais fortes com seus stakeholders, podendo assim ser mais valorizadas em diferentes mercados de capitais (Heal, 2005; Matsumura, Prakash, \& Vera-Muñoz, 2013; Dhaliwal, Li, Tsang, \& Yang, 2014).

Sob a perspectiva de risco, a RSC está recebendo cada vez mais atenção tanto por pesquisadores quanto por gestores empresariais, devido à sua capacidade de construir e aprimorar a imagem corporativa, melhorando sua relação com stakeholders e a performance das empresas como um todo (Vasi \& King, 2012; Sun \& Cui, 2014). O risco ambiental é um dos fatores que influenciam o risco de crédito de várias maneiras (Mengze \& Wei, 2015). Ao analisarem a performance de bancos de 120 países que concedem créditos em linhas ambientais também chamadas de linhas verdes Mengze e Wei (2015) encontraram que para a concessão de crédito os analistas profissionais precisam estudar o efeito das vulnerabilidades ambientais de uma empresa na geração de recursos. E neste sentido Mengze e Wei (2015) e Vasi e King (2012) fazem um alerta aos investidores e à comunidade empresarial como um todo ao recomendar mais cuidados quando o assunto é a concessão de crédito com linhas de crédito relacionadas à responsabilidade ambiental.

Empresas podem sofrer riscos diretos, devido à responsabilidade de limpeza de contaminação causada por um possível acidente ambiental ou atividade que prejudique ao meio ambiente, podendo gerar penalidades financeiras (Mengze \& Wei 2015; Vasi \& King 2012; Erragragui, 2017). Esses acontecimentos podem reduzir a rentabilidade e os fluxos de caixa e, consequentemente, a capacidade de pagamento de empréstimos. Alguns estudos trazem ainda que as empresas mais visadas pela população, como as que operam nos seguimentos de produtos químicos, papel e celulose e metalurgia, são mais propensas à redução de custos por meio de gerenciamento de riscos e melhor relacionamento com stakeholders (Stefan \& Paul, 2008; Heras-Saizarbitoria, Molina-Azorín, \& Dick, 2011).

Os bancos, por exemplo, podem ter sua reputação prejudicada caso concedam financiamento para projetos empresariais considerados como "não amigos" do meio ambiente, mesmo que o banco esteja atuando em plena conformidade com a lei (Weber, 2005; Herman, Reis, Ribeiro e Rezende, 2009; Coulson, 2009; Sun \& Cui, 2014; Mengze \& Wei, 2015).

Em relação à metodologia empregada, foi utilizado o modelo de regressão linear "difference in differences" com efeito fixo, que capta o efeito da obtenção da certificação no grupo de tratamento, comparando com as empresas que fazem parte do grupo de controle. A proxy para representar a sustentabilidade ambiental utilizada neste estudo foi a informação de que a empresa é certificada na ISO 14001. A abordagem foi descritiva, a coleta de dados foi secundária e foram utilizados dados da Econo- 
mática com relação às informações financeiras estudadas. Um Propensity Score Matching também foi efetuado para se mitigar um possível viés de auto seleção. Os resultados sugerem que embora a adoção de práticas de gerenciamento exigidas pelos padrões ISO14001 não reduza em média o risco sistêmico das empresas, percebe-se alteração na estrutura de capital das empresas certificadas a partir da redução do custo de capital de terceiros e aumento da proporção da dívida de longo prazo.

A contribuição desse trabalho está ligada ao fato de que após as análises estatísticas, é possível apoiar a promoção de estratégias envolvendo responsabilidade ambiental, em especial, a certificação ISO 14001. Este estudo também contribuir na tomada de decisão dos gestores que se esforçam para manter a empresa com boa condição econômica e financeira, com estrutura de dívida otimizada, com menor custo de capital e prazos mais extensos (Sun \& Cui, 2014). Além disso, espera-se que as empresas se motivem a fortalecer seu gerenciamento ambiental nas operações diárias de forma a resguardar o meio ambiente de forma estratégica, ou seja, sinalizando de forma consciente e com o mínimo de assimetria, de modo a aumentar a competitividade e promover o desenvolvimento empresarial em todos os aspectos a longo prazo.

\section{FUNDAMENTAÇÃO TEÓRICA}

\subsection{Responsabilidade Ambiental}

A degradação ambiental está significativamente relacionada às atividades empresariais. Dessa forma, a responsabilidade ambiental já é vista como um requisito básico para funcionamento de algumas empresas, principalmente as indústrias mais expostas a riscos ambientais (Mackey, Mackey, \& Barney, 2007; Weber, 2005, Herman, Reis, Ribeiro e Rezende, 2009; Coulson, 2009, Paulraj \& De Jong, 2011; Sun \& Cui, 2014; Mengze \&Wei, 2015). Isso leva os gestores a reexaminarem seus produtos e processos, com o objetivo de reduzir ao mínimo possível os resíduos da sua produção, sem sacrificar a qualidade de seus produtos e seus custos que será explicado mais a frente (Ex: ISO 14001). Afinal, é preciso haver um benefício tanto ambiental quanto financeiro para que as empresas estejam motivadas a longo prazo em se manterem certificadas e cumprindo os requisitos propostos em prol do meio ambiente (Song et al., 2017). Neste sentido, Christmann (2000), Rao and Holt, (2005), Zeng, Tam, Vivian, \& Deng (2005), Matuszak-Flejszman (2009), Yang, Tam, Vivian, \& Deng (2011), Ferron, Funchal, Nossa, \& Teixeira (2012), e Zhu, Cordeiro, \& Sarkis (2013) afirmam que empresas certificadas em média são mais lucrativas do que empresas não certificadas.

Embora a RSA possa promover melhorias inovadoras no meio produtivo, resultando em tecnologias mais eficientes, processos mais limpos, menos perdas e retrabalhos possivelmente alcançando novos mercados e uma vantagem competitiva (Song et al., 2017), quando se fala em gastos com gestão ambiental, muitos dos líderes empresariais os encaram como um "fardo financeiro". Isso porque a implementação de estratégias ambientais, inevitavelmente, precisa de investimentos financeiros. Esse gasto inicial para implementação dos novos processos sugeridos para uma melhor gestão ambiental, pode implicar, por exemplo, na alteração de um portfólio de produtos ou no lançamento de novos processos organizacionais, gerando aumento nos custos de produção (Christmann, 2000; Matuszak-Flejszman, 2009; \& Massoud et al., 2010, Martín-de Castro et al, 2015).

Entretanto, algumas empresas acreditam que desenvolvendo suas capacidades ambientais estarão se prevenindo de um futuro cenário de esgotamento dos recursos naturais, como o caso da Panasonic, uma líder de mercado ambientalmente pró-ativa que se concentra no gerenciamento verde e de 
sustentabilidade (Martín-de Castro (2015); Lee, Min, \& Yook, 2015). Neste sentido, podem minimizar os riscos de acidente ambiental ao mesmo tempo em que maximizam as novas oportunidades de negócios e aumentam o investimento de longo prazo, assim obtendo um desempenho financeiro e ambiental superior, bem como uma vantagem competitiva (Lee et al., 2015).

Ao analisar diferentes mercados Weber (2005), Herman, Reis, Ribeiro e Rezende (2009), Coulson (2009), Sun \& Cui (2014), Mengze e Wei (2015) concordam que ao financiar empresas por meio de linhas de crédito verde ou linhas de crédito ambientais as entidades fornecedoras de capital precisam ficar atentas aos relatórios de sustentabilidade, no sentido de monitorar a aplicação do crédito. Em casos nos quais as entidades fornecedoras de crédito não observam tais relatórios há risco de elas terem as suas imagens abaladas, principalmente quando a empresa financiada se envolve em acidentes ambientais.

Os processos de padronização e certificação são ferramentas de diferenciação de mercado para as empresas, em especial, para esse contexto, a ISO 14001 (Montabon, Melnyk, Sroufe, \& Calantone, 2000; To \& Tang, 2014). A certificação pode gerar muito mais do que benefícios organizacionais e ambientais, pode gerar benefícios econômicos (Bansal \& Bogner, 2002). A capacidade de vender para clientes que exigem produtos ecológicos e atividades mais sustentáveis, como a industrial automobilística, que há quase duas décadas exige que seus fornecedores sejam certificados na ISO 14001, é uma tendência que vem se estendendo por outros setores industriais. No momento em que as empresas respondem a estas exigências, podem obter uma vantagem competitiva em relação aos seus concorrentes que não possuem certificação (Christmann, 2000; Bansal \& Bogner, 2002; Rao and Holt, 2005, Zeng et al., 2005, Matuszak-Flejszman, 2009, Yang et al., 2011, Ferron et al., 2012, Zhu et al., 2013).

Dentro do SGA, a ISO 14001 é um dos padrões internacionais mais difundidos e um dos mais adotados, devido à sua intenção de motivar qualquer tipo de organização a operar sob práticas ambientais, independente do seu setor de atuação, do seu porte ou da sua localização geográfica (Paulraj \& De Jong, 2011). A certificação ISO 14001 é uma garantia aos stakeholders de que a empresa está engajada em realizar seu trabalho principal, seja ele qual for, de forma ambientalmente sustentável (Hojnik, Ruzzier, \& Antoncic, 2017). Diante disso, a sinalização ambiental por meio da ISO 14001 pode fornecer uma imagem melhorada da empresa, sendo assim, uma ferramenta para desenvolver vantagem competitiva.

\subsection{Sinalização/Divulgação Ambiental}

A prática de divulgação ambiental vem ganhando destaque, nos últimos anos, e o número de empresas que sinalizam suas atividades em prol da sustentabilidade ambiental vem aumentando (Ahmadi, 2017). A literatura passada que abordou a relação entre a divulgação sobre a RSA e o custo do capital, sugere que essas influências no custo do capital podem ser explicadas por uma redução na assimetria de informações (El Ghoul, Guedhami, Kwok, \& Mishra, 2011; Teixeira et al., 2011; Clarkson, Fang, Li, \& Richardson, 2013). Além disso, a divulgação das atividades socioambientais pode influenciar o custo do capital próprio pelos efeitos de preferência dos investidores, caso eles estejam dispostos a aceitar um menor retorno esperado sobre investimentos que necessariamente atinjam objetivos socioambientais (Richardson \& Welker, 2001). A ideia é que a sinalização da responsabilidade ambiental possa ser uma razão pela qual empresas sejam impactadas em seu desempenho financeiro.

Isso sugere que as empresas que não só buscam sinalizar por meio da certificação, mas que também se esforçam por intermédio de um compliance ambiental, estão cientes de que essa sinalização e esse comprometimento das regulamentações ambientais refletem bem à reputação da empresa (Mcguire, 2014). Afinal, a norma ISO 14001 se baseia nos princípios tradicionais de gerenciamento (planejar, exe- 
cutar, verificar, agir) e sua implementação é verificada por meio de auditorias periódicas cujo objetivo é garantir que as partes interessadas cumpram com os requisitos da norma ISO 14001, caso contrário, perdem a certificação (Dogui et al., 2014).

De modo geral, a informação afeta os processos de tomada de decisão usados por indivíduos em diversos contextos, tanto familiares quanto empresariais e governamentais, tendo por base informações públicas disponíveis gratuitamente ou privadas, que estão disponíveis apenas para um subconjunto do público (Spence, 1973).

Sinalizar informações credíveis pode funcionar como um filtro e implicar na tomada de decisão (Spence, 2002). Diante disso, a sinalização de RSA pelas empresas, que no caso da ISO 14001, pode acorrer por meio de anúncios públicos, dos seus sites e também por intermédio de impressão do símbolo de certificação nos rótulos de seus produtos finais. A sinalização ambiental pode aumentar a previsibilidade de suas ações perante ao mercado através dos sinais de transparência que aumentam o valor da mesma (Clarkson et al., 2013; Castka \& Balzarova, 2018). Dessa forma temos:

H1: A sinalização da responsabilidade ambiental reduz o custo de capital da empresa.

Por um lado, quando as divulgações são voluntárias melhoram ainda mais as percepções dos investidores que tendem a reduzir incertezas, aumentando assim a avaliação das empresas (Hojnik, Ruzzier, \& Antoncic, 2008). Por outro lado, quando se trata de relatórios voluntários, por não seguirem nenhum critério, dificultam a análise dos stakeholders em determinar quais empresas são realmente eficientes nesse quesito ambiental (Mahoney, \& Robert, 2007).

Diante disso, a sinalização de sustentabilidade ambiental por meio de informações credíveis, como é o caso da ISO 14001, podem auxiliar a mostrar para os investidores uma conduta empresarial sustentável confiável de forma mais transparente antes de investir na empresa (Jenkins \& Yakovleva, 2006; Lock \& Seele, 2015). Jenkins \& Yakovleva (2006), trazem em seu trabalho essa questão com foco no setor de mineração, mostrando o quanto a divulgação ambiental é fundamental para indústrias mais expostas ao risco ambiental.

\subsection{Responsabilidade Ambiental sob a ótica de risco, custo de capital e dívida.}

m Song et al. (2017) a partir de seus resultados encontrados após análise de 2827 empresas na China, confirmam que a RSA pode melhorar o desempenho financeiro futuro (com exceção do $1^{\circ}$ ano), através do uso eficiente de recursos que por sua vez geram maior reputação e competitividade. Seus resultados são compatíveis com Heal (2005), acrescentando que o comportamento ambiental responsável pode reduzir o risco comercial, o que interfere diretamente no custo de capital. A lógica por trás disso é que as empresas tendem a se tornar mais seguras e estáveis, o que melhora as relações com as autoridades reguladoras e diminui a incidência de penalidades.

O fornecedor de crédito também se compromete na medida que as empresas financiadas se envolvem em acidentes. Desta forma, Weber (2005), Herman, Reis, Ribeiro e Rezende (2009), Coulson (2009), Sun \& Cui (2014), Mengze e Wei (2015) estudam a relação de entidades financiadoras, por meio de linha de crédito verde ou linha de crédito ambiental. Tais autores corroboram a ideia de que a entidade que fornece a linha de crédito precisa ficar atento ao cumprimento do investimento proposto, deve analisar relatórios de sustentabilidade ambiental e monitorar a empresa periodicamente. Este tipo de iniciativa pode ajudar a reduzir o risco de crédito e ainda pode evitar o risco de ter a sua imagem atrelada a um 
acidente ambiental de uma entidade financiada. (Weber, 2005; Herman, Reis, Ribeiro, \& Rezende, 2009, Coulson, 2009, Sun \& Cui, 2014, \& Mengze \& Wei, 2015)

Cellier e Chollet (2016) afirmam que uma alta performance de desempenho ambiental pode afetar o risco sistêmico de uma empresa por uma variedade de razões. Sob o ponto de vista do acionista, as empresas poluidoras são mais arriscadas por estarem mais expostas a desastres ambientais, ou seja, expostas a riscos ambientais. Este tipo de cenário pode não oferecer segurança ao investidor. Por esse motivo, tais empresas são de interesse por poucos acionistas, tendem a ser mais baratas, menos compartilhadas e consequentemente seus retornos esperados tendem a ser maiores (Cellier \& Chollet, 2016). Já sob o ponto de vista da empresa, uma gestão eficaz de risco ambiental e bons padrões de RSC estão associados a menores custos de dívida por sua capacidade de construir uma forte imagem corporativa e reputação, os preços das ações tendem a ser mais altos, assim como o desempenho da empresa (Christmann, 2000; Bansal \& Bogner, 2002; Rao \& Holt, 2005; Zeng et al., 2005; Mackey et al., 2007; Sharfman \& Fernando, 2008; Matuszak-Flejszman, 2009; Yang et al., 2011; El Ghoul et al., 2011; Ferron et al., 2012; Zhu et al., 2013; Cellier \& Chollet, 2016; Erragragui, 2017).

Na medida que a empresas tomam providências em prol do meio ambiente por intermédio de medidas estratégicas que reduzem as emissões e a poluição, isso tende a melhorar como um todo a relação dessas firmas com reguladores governamentais ou de partes interessadas, reduzindo assim os conflitos de interesse e promovendo o entendimento entre as partes (Brasil, 2000; Sharfman \& Fernando, 2008). Ao melhorar a gestão ambiental as empresas podem obter subsídios governamentais, recompensas, reduções de impostos ou descontos fiscais por meio da proteção ambiental e da transformação de energia (Song et al., 2017). Isso ocorre, pois essas decisões tendem a reduzir os riscos sistêmicos imediatos e futuros que possuem um nível de impacto financeiro incerto.

Os investidores e os analistas levam em consideração fatores de Responsabilidade Ambiental ao tomar decisões e recomendações de investimento (Christmann, 2000; Bansal \& Bogner, 2002; Rao \& Holt, 2005; Zeng et al., 2005; Mackey et al., 2007; Sharfman \& Fernando, 2008; Matuszak-Flejszman, 2009; Yang et al., 2011; El Ghoul et al., 2011; Ferron et al., 2012; Zhu et al., 2013; Cellier \& Chollet, 2016; Erragragui, 2017).

Com relação a Gestão do Risco de Crédito Ambiental que vem ganhando uma atenção crescente nos últimos anos, defendendo que os riscos ambientais podem afetar mais precisamente, a percepção de risco de mercado da empresa (Weber, 2012). Diante disso, temos a segunda hipótese a ser testada:

H2: A sinalização ambiental reduz o risco da empresa.

Dessa forma, empresas ambientalmente responsáveis podem ter risco (Beta) reduzido, e essa possível redução, pode fazer com que o mercado aceite prêmios de risco inferiores ou proporcione maior alavancagem para a empresa, podendo resultar em um menor custo de capital (Sharfman \& Fernando, 2008). Apesar de que após análise dos resultados, Clarkson et al. (2013), não confirmou sua hipótese que relacionava divulgação ambiental e o custo do capital.

Um estudo realizado na década de 90 mostrou que cerca de 10\% de todas as perdas de crédito nos bancos alemães estavam envolvidos riscos ambientais (Erragragui, 2017). Weber (2012) e Erragragui (2017) associaram esses danos ao aumento nos custos ambientais provenientes da gestão de desastres (Erragragui, 2017). Diante disso, se o mercado perceber melhorias após a certificação ISO 14001, mas não perceber mudanças no risco, o custo do capital tende a permanecer igual (Sharfman \& Fernando, 2008). Em contrapartida, se as mudanças no risco percebido após a certificação levam à redução do 
custo de capital, isso pode aumentar a capacidade de aumentar a dívida, de forma consequente. Diante disso, temos:

H3: A sinalização ambiental interfere no montante de dívida da empresa.

As práticas verdes estão relacionadas ao futuro valor de mercado da empresa, bem como a futura rentabilidade da empresa (Stefan \& Paul, 2008). Portanto, este estudo busca examinar empiricamente e testar a relação entre a certificação ambiental como mecanismo de sinalização de sustentabilidade e o custo da dívida das empresas. Ou seja, se as iniciativas de responsabilidade ambiental afetam os riscos sistêmico e a estrutura de capital das empresas.

\section{METODOLOGIA}

Para que fosse possível verificar o efeito da sinalização de responsabilidade ambiental na estrutura de capital, risco e nível de endividamento, inicialmente foram obtidos dados financeiros e de mercado das empresas brasileiras com ações negociadas na B3 junto à base de dados Economática. A certificação ISO 14001 obtida junto à ISO foi empregada como proxy de sinalização para empresas que são comprometidas com sustentabilidade ambiental. Os dados coletados se referem ao período de 1995 a 2016, sendo a amostra inicial composta por 7480 observações de empresas de 19 setores segundo classificação Economática, com exceção das seguradoras e instituições financeiras, dadas as particularidades da formação da estrutura de capital das empresas desse setor. Após a exclusão de empresas que não apresentavam informações sobre variáveis financeiras e de mercado necessárias à realização do estudo, obteve-se uma amostra final de 2365 firmas-ano.

Como metodologia estatística empregada, utilizou-se um modelo "difference in difference" com efeito fixo para empresa, com o intuito de se estimar o efeito da obtenção da certificação na estrutura de capital, risco e nível de endividamento mediante a comparação de empresas que receberam a respectiva certificação do Sistema de Gestão Ambiental com empresas que não possuem tal certificação. $O$ conjunto de empresas brasileiras com certificação ISO14001 compõem o grupo de tratamento, enquanto empresas que não possuem tal certificação compõe o grupo de controle.

Para o caso em análise, a utilização do estimador de painel com efeito fixo por empresa é necessária uma vez que tal estimador controla por características de cada empresa fixas no tempo e que estão relacionados à sinalização ambiental e estrutura de capital. Schlischka et al. (2009), por exemplo, apresentam evidências de que instituições financeiras levam em consideração nas análises de concessão de créditos itens como ocorrência de passivos ambientais, impactos ambientais, exigências de licenças e pareceres ambientais, dentre outros. Tais características estão intrinsicamente relacionadas ao operacional de cada empresa, incluindo variáveis como setor de atuação e classificação de firmas altamente poluidoras (características fixas no tempo), e são na média controladas por meio do referido estimador.

Para testar a Hipótese 1 de que a sinalização ambiental reduz o custo de capital das empresas, utilizou-se o Modelo de regressão a seguir

CUSTOi, $t=\pi j+\alpha t+\beta 1 D I D i t+\beta 2$ DGrupoi.D1 ${ }^{\circ}$ ano $+\beta 3 R O A i, t+\beta 4$ Riscoi, $t+\beta 5$ Liquidezi, $t+\beta 6$ Tangibilidadei, $t+\beta 7$ Tamanhoi, $t+\beta 8$ Pcirci,t+ $\beta$ P PNcirci, $t+i, t$

em que CUSTO $_{i, t}$ se refere ao custo médio ponderado de capital da empresa i no tempo t, DID $_{i t}$ é uma dummy que assume o valor 1 para para empresas certificadas nos anos posteriores à certificação, DGru- 
po é uma dummy igual a 1 para empresas que receberam a certificação, e $\mathrm{D} 1^{\circ}$ ano é uma dummy que assume o valor 1 para o ano de certificação.

No modelo 1, o coeficiente $\beta$ da variável DIDit representa o efeito em média da certificação ISO14001 no custo ponderado de capital, enquanto $\beta_{2}$ indica o efeito que a certificação produz sobre o custo de capital no ano de certificação (efeito de curto prazo). De acordo com a Hipótese 1 de que a sinalização ambiental reduz o custo de capital das empresas, espera-se que ambos os coeficientes $\beta_{1}$ e $\beta_{2}$ assumam valores negativos.

Para controlar por heterogeneidades existentes entre as empresas que compõe o grupo de controle e tratamento, foram utilizadas ainda as seguintes variáveis de controle: Retorno sobre o ativo (ROA), que pode ser percebida como um determinante positivo da capacidade de reembolso das empresas, esperando assim que esteja negativamente associada ao custo da dívida (Erragragui, 2017); e Liquidez, estimada pela liquidez geral (Ativo circulante + realizável a longo prazo/ Passivo circulante + exigível longo prazo), uma vez que baixa liquidez está associada a maiores riscos e até mesmo à elevação da probabilidade de falência da empresa (Araujo, Ferreira, \& Funchal, 2012). Por outro lado, empresas com altos níveis de liquidez podem utilizá-la para financiar seus investimentos (Serghiescu \& Văidean, 2014).

Utilizou-se como controle ainda a Tangibilidade, mensurada como a relação entre os ativos fixos e totais da empresa. Empresas que possuem maior proporção de ativos tangíveis podem ter seu custo da dívida reduzido na medida em que ativos tangíveis servem como garantia para a contração de empréstimos, sendo percebida pelos investidores como um fator positivo (Serghiescu \& Văidean; 2014).

Para controlar por heterogeneidades associadas ao tamanho, utilizou-se o In do ativo total. Especificamente, evidências da literatura sugerem que empresas maiores possuem menor risco de falência e maior capacidade de endividamento (Serghiescu \&Văidean; 2014). Além disso, segundo Song et al. (2017), grandes empresas tendem a estar mais expostas à atenção do público, intensificando assim a sua atenção com sua responsabilidade ambiental e social, e, por sua vez, a divulgação dessas ações socioambientais.

Especificamente com relação à variável dependente CUSTO $_{i, t^{\prime}}$ utilizou-se a média ponderada do custo de capital próprio e de terceiros (Weighted Average Capital Cost - WACC), tal como em Clarkson et al. (2013):

$$
W A C C=(\% P O \times K i)+(\% P L \times K e) .
$$

sendo:

WACC $=$ taxa de custo médio ponderado do capital;

\%PO = participação de capital de terceiros na estrutura de capital da empresa;

$\mathrm{Ki}=$ custo de capital de terceiros;

Ke = Custo de capital próprio.

\% PL = participação de capital próprio na estrutura de capital da empresa;

O custo do capital próprio (Ke) foi estimado a partir do Capital Asset Pricing Model (CAPM), modelo que combina risco e retorno e é utilizado para mensurar o prêmio pelo risco esperado das ações (Damodaran, 2002; Teixeira et al., 2011). Para a estimação do custo de capital próprio a partir do CAPM, levou-se em consideração o prêmio pelo risco de mercado com base na economia dos Estados Unidos a fim de minimizar os efeitos de volatilidade dos índices financeiros do mercado de ações do Brasil (Assaf Neto, Guasti Lima, \& Procópio de Araújo, 2013), tal como:

Custo de Capital Próprio $=$ Rf Americana $+\beta($ Rm Americana - Rf Americana $)+$ Risco Pais $+($ Inflação Brasileira - Inflação Americana)]

As fontes dos dados utilizados para a estimação do CAPM seguem apresentadas no quadro 1. 
Quadro 1: Variáveis CAPM. Fonte: Elaborado pelos autores.

\begin{tabular}{|c|c|}
\hline VARIÁVEIS & FONTE \\
\hline Taxa de Retorno Livre de Risco (Rf) - Americano :T-Bond & https://www.federalreserve.gov/ \\
\hline Beta - $\beta$ : Risco sistemático de mercado da empresa & Base de Dados Economática \\
\hline Taxa de Retorno da Carteira de Mercado (Rm) - Americano & https://www.federalreserve.gov/ \\
\hline Risco Pais ou Risco Brasil & http://www.ipeadata.gov.br/Default.aspx \\
\hline
\end{tabular}

Para que seja possível responder a Hipótese 2 que trata do efeito da sinalização ambiental no risco da empresa, utilizou-se o Modelo de regressão:

Risco $_{i, t}=\pi_{i}+\alpha_{t}+\beta_{1} D_{I} D_{i t}+\beta_{2} D_{\text {Grupo }} D^{\circ} 1^{\circ}$ ano $+\beta_{3} R O A_{i, t}+\beta_{4}$ Liquidez $_{i, t}+\beta_{5}$ Tangibilidade $_{i, t}+\beta_{6}$ Tamanho $_{i, t}+\beta_{7}$ Pcirc $_{i, t}+\beta_{8}$ PNCirc $_{i, t}+\varepsilon_{i, t}$

em que Risco ${ }_{i, t}$ se refere ao risco da empresa e foi mensurado pelo Beta do CAPM disponível no Econo-

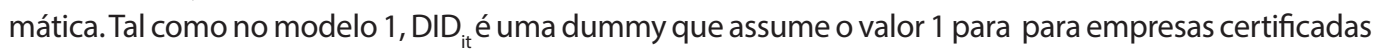
nos anos posteriores à certificação, DGrupo é uma dummy igual a 1 para empresas que receberam a certificação, e D1ªno é uma dummy que assume o valor 1 para o ano de certificação.

O beta da empresa é função da incerteza com relação às atividades futuras da firma (Orlitzky \& Benjamin, 2001; Sharfman \& Fernando, 2008). Quanto maior for essa incerteza, menor a qualidade de crédito avaliada de sua dívida e, consequentemente, maior será seu custo de financiamento. Conforme hipótese 2, espera-se que a certificação ISO14001 reduza o risco da empresa. Nesse caso, espera-se que os coeficientes $\beta_{1}$ e $\beta_{2}$ do modelo 2 assumam valores negativos, uma vez que o coeficiente $\beta_{1}$ da variável DID $D_{\text {it }}$ representa o efeito em média da certificação ISO14001 no risco, enquanto $\beta_{2}$ indica o efeito que a certificação produz sobre o risco no ano de certificação (efeito de curto prazo).

Para que seja possível testar a Hipótese 3 que trata do efeito da sinalização ambiental no montante de dívida da empresa, utilizou-se o modelo de regressão 3:

Dívida $_{i, t}=\pi_{j}+a_{t}+\beta_{1}$ DID $_{i t}+\beta_{2}$ DGrupo $_{i} 1^{\circ}$ ano $+\beta_{3} R O A_{i, t}+\beta_{4}$ Risco $_{i, t}+\beta_{5}$ Liquidez $_{i, t}+\beta_{6}$ Tangibilidade $_{i, t}+\beta_{7}$ Tamanho $_{i, t}+\varepsilon_{i, t}$

no qual Dívida representa a proporção da soma das dívidas de curto prazo (passivo circulante) e longo prazo (passivo não circulante) em relação ao ativo total da empresa. As demais variáveis, incluindo as de controle, seguem definidas tais como nos dois modelos anteriores.

No modelo 3, o coeficiente $\beta_{1}$ da variável DID ${ }_{\text {it }}$ representa o efeito em média da certificação ISO14001 no endividamento total da empresa, enquanto $\beta_{2}$ indica o efeito que a certificação produz sobre a dívida total no ano de certificação (efeito de curto prazo). De acordo com a Hipótese 3 de que a sinalização ambiental possui influência na dívida das empresas, espera-se que ambos os coeficientes $\beta_{1}$ e $\beta_{2}$ sejam significativos, sendo valores positivos (negativos) associados à aumento (redução) da dívida. O quadro 2 reúne todas as variáveis dependentes, independentes e de controle citadas anteriormente.

Quadro 2: VD: Variáveis Dependentes. VI: Independentes. VC: Variável de Controle

\begin{tabular}{|c|c|c|}
\hline VARIÁVEIS & TIPO & DEFINIÇÃO \\
\hline Custo & VD & Custo do Capital, mensurado por meio do WACC \\
\hline Risco & VD & Risco da empresa, mensurado por meio do Beta do CAPM \\
\hline Dívida & VD & $\begin{array}{l}\text { Proporção da soma dos Passivos Circulante e Não-Circulante em relação ao } \\
\text { Ativo Total. }\end{array}$ \\
\hline DID & $\mathrm{Vl}$ & $\begin{array}{c}\text { Variável cujo coeficiente representa o estimador de diferenças-em-diferenças } \\
\text { Assume o valor } 1 \text { para empresas certificadas nos anos posteriores à } \\
\text { certificaçãa, e } 0 \text { caso contrário. }\end{array}$ \\
\hline Dgrupo & $\mathrm{Vl}$ & $\begin{array}{l}\text { Dummy de grupo que assume o valor } 1 \text { para empresas do grupo de } \\
\text { tratamento (com certificação ISO14001) e } 0 \text { para empresas do grupo de } \\
\text { controle (empresas que não possuem tal certificação). }\end{array}$ \\
\hline
\end{tabular}




\begin{tabular}{|c|c|c|}
\hline D1 Ano & VI & $\begin{array}{c}\text { Dummy que assume o valor 1 para o ano em que a empresa do grupo de } \\
\text { tratamento recebeu a certificação ISO14001 }\end{array}$ \\
\hline ROA & VC & $\begin{array}{c}\text { Lucro, Líquido sobre o Ativo Total } \\
\text { Liquidez }\end{array}$ \\
\hline VC & Passivo circulante + exigível longo prazo). \\
\hline Tangibilidade & VC & Imobilizado/Ativo Total \\
\hline Tamanho & VC & Ln (Ativo Total) \\
\hline Pcirc & VC & Passivo Circulante / Ativo Total \\
\hline PNcirc & VC & Passivo não Circulante / Ativo Total \\
\hline
\end{tabular}

Fonte: Elaboração pelos autores

\section{RESULTADOS DA PESQUISA}

\subsection{Resultados da estatística descritiva}

A Tabela 1 apresenta a estatística descritiva das 2365 firmas-ano utilizadas neste trabalho. Todos os dados foram winsorizados a 2,5\% para mitigar a possível influência de outliers e permitir a comparabilidade com outros estudos.

Conforme verificado na Tabela 1, na média a participação de capital próprio nas empresas brasileiras listadas corresponde por quase dois terços do capital total das empresas (63\%). Tal participação é maior que percentuais de países com mercado de capitais mais desenvolvidos e menores custos de financiamento. Isso pode ser explicado pelo perfil comum entre empresas Brasileiras, as quais por serem familiares utilizam em maior parte recursos próprios (Albanez, 2015). O custo de capital médio das empresas foi de $12 \%$, valor comparável à outros resultados da literatura nacional. O custo de capital de terceiros com média de 7\% apresentou-se variando em um intervalo de 4\% 4 11\%. Tais custos evidenciam o maior custo de financiamento enfrentado pelas empresas brasileiras (Funchal \& Monte-Mor, 2016).

\section{Tabela 1: Estatística Descritiva}

Os dados abaixo se referem à estatística descritiva referente às variáveis utilizadas para se estimar o efeito da certificação ISO14001 no custo de capital, nível de endividamento e risco das empresas brasileiras listadas na B3. Dados financeiros e de mercado foram obtidos junto à base de dados Economática. A certificação ISO 14001 obtida junto à ISO foi empregada como proxy de sinalização para empresas que são comprometidas com sustentabilidade ambiental. Os dados coletados se referem ao período de 1995 a 2016, cuja amostra final foi composta por 2365 firmas-ano. Além dos indicadores WACC (custo médio ponderado de capital), percentual de participação de capital próprio e de terceiros, custo de capital próprio e de terceiros, beta (risco do CAPM), dívida total, de curto e de longo prazo, foram apresentadas informações sobre as variáveis de controle Endividamento; ROA (retorno sobre o ativo); passivo circulante (Dívida de CP); passivo não circulante (Dívida de LP), Liquidez Geral, Tangibilidade e Tamanho das empresas (In do ativo total).

\begin{tabular}{|c|c|c|c|c|c|c|c|c|}
\hline Variáveis & No Obs & Média & Desvio Pad. & Min & Q1 & Mediana & Q3 & Max \\
\hline \% Particip cap. Terc. & 2365 & 0,37 & 0,23 & 0,00 & 0,19 & 0,36 & 0,53 & 0,98 \\
\hline \% Part Cap. Próp. & 2365 & 0,63 & 0,23 & 0,02 & 0,47 & 0,64 & 0,81 & 1,00 \\
\hline Custo Cap. Terc.. & 2365 & 0,07 & 0,02 & 0,04 & 0,06 & 0,07 & 0,08 & 0,11 \\
\hline Custo Cap. Próp. & 2365 & 0,38 & 0,80 & 0,00 & 0,10 & 0,16 & 0,29 & 4,96 \\
\hline WACC & 2365 & 0,12 & 0,07 & 0,01 & 0,07 & 0,10 & 0,13 & 0,40 \\
\hline Beta & 2365 & 0,69 & 0,44 & $-1,08$ & 0,38 & 0,67 & 0,95 & 2,61 \\
\hline Endividamento & 2365 & 0,57 & 0,19 & 0,03 & 0,44 & 0,57 & 0,70 & 1,00 \\
\hline Dívida CP & 2365 & 0,28 & 0,15 & 0,00 & 0,17 & 0,25 & 0,35 & 0,98 \\
\hline Dívida LP & 2365 & 0,29 & 0,16 & 0,00 & 0,15 & 0,29 & 0,40 & 0,89 \\
\hline ROA & 2365 & 0,03 & 0,09 & $-1,24$ & 0,00 & 0,04 & 0,07 & 0,22 \\
\hline Liquidez & 2365 & 1,13 & 0,88 & 0,06 & 0,65 & 0,92 & 1,33 & 11,56 \\
\hline Tangibilidade & 2365 & 0,59 & 0,22 & 0,01 & 0,42 & 0,63 & 0,77 & 0,99 \\
\hline Tamanho & 2365 & 14,51 & 1,79 & 9,39 & 13,27 & 14,71 & 15,84 & 17,57 \\
\hline
\end{tabular}




\subsection{Resultados da estatística descritiva}

A Tabela 2 apresenta o teste de diferença de médias com relação às variáveis analisadas nesse estudo antes da certificação. $O$ objetivo desse teste é averiguar no período antes da certificação se as empresas do grupo de tratamento, ou seja, que obtiveram a certificação, são iguais ou diferentes em média das empresas que não possuem certificação. O teste foi aplicado considerando o período de 1995 a 2016, totalizando um período amostral de 21 anos.

\section{Tabela 2: Teste de Diferença de Médias}

Esta tabela apresenta resultados de um teste t diferença de médias para as variáveis da estrutura de capital e controles utilizadas neste trabalho. O objetivo deste teste é verificar as diferenças existentes entre as empresas certificadas e não certificadas antes da certificação.

\begin{tabular}{|c|c|c|c|c|c|c|}
\hline \multirow{2}{*}{ Variáveis } & \multicolumn{2}{|c|}{ Empresas Sem Certificação } & \multicolumn{2}{|c|}{ Empresas Certificadas } & \multirow{2}{*}{$\begin{array}{l}\text { Diferença de } \\
\text { Médias }\end{array}$} & \multirow{2}{*}{ P-Valor } \\
\hline & Média & Desvio Padrão & Média & Desvio Padrão & & \\
\hline \% Particip cap. Terc. & 0,37 & 0,243 & 0,35 & 0,216 & 0,03 & 0,11 \\
\hline \% Part Cap. Próp. & 0,63 & 0,24 & 0,65 & 0,22 & $-0,03$ & 0,11 \\
\hline Custo Cap. Terc.. & 0,38 & 0,76 & 0,64 & 1248,00 & $-0.264^{* * *}$ & 0,00 \\
\hline Custo Cap. Próp. & 0,07 & 0,02 & 0,07 & 0,02 & $-0.096^{* * *}$ & 0,00 \\
\hline WACC & 0,12 & 0,07 & 0,137 & 0,09 & $-0.084^{* * *}$ & 0,00 \\
\hline Beta & 0,69 & 0,46 & 0,74 & 0,34 & $-0.053^{*}$ & 0,08 \\
\hline Dívida Total & 0,57 & 0,20 & 0,55 & 0,20 & 0,02 & 0,16 \\
\hline Dívida CP & 0,28 & 0,16 & 0,30 & 0,16 & 0,29 & 0,18 \\
\hline Dívida LP & 0,28 & 0,17 & 0,25 & 0,16 & $0.345^{* * *}$ & 0,00 \\
\hline ROA & 0,02 & 0,10 & 0,03 & 0,06 & 0,00 & 0,60 \\
\hline Liquidez & 1,19 & 1,00 & 1,13 & 0,80 & 0,06 & 0,34 \\
\hline Tangibilidade & 0,58 & 0,23 & 0,59 & 0,21 & $-0,02$ & 0,26 \\
\hline Tamanho & 14,13 & 1,72 & 14,56 & 1,75 & $-0.430^{* * *}$ & 0,00 \\
\hline
\end{tabular}

Fonte: Elaborado pelos autores. Nota: Os símbolos ***, **e $e^{*}$ indicam que diferenças significativas aos níveis de 1\%, 5\% e 10\%, respectivamente.

Por se tratar de um cenário anterior à certificação, o número de observações das empresas certificadas é de 243, enquanto que o das não certificadas é de 1525. A explicação pela escolha desse período está relacionada ao fato de possibilitar o conhecimento das características naturais das empresas antes do evento externo, no caso a certificação ISO 14001.

Com 99\% de confiança, em média as empresas que em algum momento se certificaram são empresas com maior custo de capital, tanto na perspectiva de custo de capital próprio (Ke), quando de terceiros (Ki). Da mesma forma, com 90\% de confiança se apresentou o risco. Este resultado mostra que antes de se certificarem as empresas já eram naturalmente mais arriscadas, e por sua vez, já apresentavam custo de capital maior.

Assim como abordado em outros estudos como o de Sharfman e Fernando. (2008), Clarkson et al. (2013), Heras-Saizarbitoria et al. (2011) e Erragragui. (2017), o setor predominante pode explicar alguns comportamentos com relação ao risco, custo de capital e dívida, sendo esses maiores em indústrias ambientalmente mais expostas a riscos. Além disso, esse também pode ser um fator que interfere diretamente no nível de sinalização da mesma (Fernandes, 2013).

Diante disso, os resultados do presente estudo estão em consonância com os demais citados acima, pois no presente estudo quase $35 \%$ da amostra é composta por empresas dos setores siderúrgico, metalúrgico e de energia elétrica que são altamente poluentes e por sua vez estão mais expostos a riscos 
ambientais. Tal fato ressalta a importância de se considerar o setor em análises que envolvem disclosures ambientais no Brasil, assim como a decisão de certificação por sistemas de gerenciamento ambiental.

Na próxima subseção apresentam-se os resultados da estimação dos modelos 1, 2 e 3, que se valem do método "difference in difference" com efeito fixo para empresa. Para o caso em análise, a utilização do estimador de painel com efeito fixo por empresa é necessária uma vez que tal estimador controla por características de cada empresa fixas no tempo e que estão relacionados à sinalização ambiental e estrutura de capital. Tais características estão intrinsicamente relacionadas ao operacional de cada empresa, incluindo variáveis como setor de atuação e classificação de firmas altamente poluidoras, e são na média controladas por meio do referido estimador.

\subsection{Resultados dos modelos de regressão} 4.3.1 Efeito da certificação custo de capital.

Sobre a interface do custo de capital, o Painel A da Tabela 3 apresenta os resultados do modelo 1 considerando-se o custo ponderado médio de capital (WACC), o custo de capital próprio e o custo de capital de terceiros como variáveis dependentes. Tais especificações foram utilizadas para se testar a Hipótese 1, sob a qual espera-se que a sinalização ambiental, por meio da certificação ISO 14001, reduza o custo de capital das empresas.

Tabela 3: Efeito da Certificação ISO14001 no Custo de Capital, Nível de Endividamento e Risco.

Os dados abaixo se referem à estimação do efeito da certificação ISO14001 no custo de capital, nível de endividamento e risco das empresas brasileiras listadas na B3. Dados financeiros e de mercado foram obtidos junto à base de dados Economática. $A$ certificação ISO 14001 obtida junto à ISO foi empregada como proxy de sinalização para empresas que são comprometidas com sustentabilidade ambiental. Os dados coletados se referem ao período de 1995 a 2016, cuja amostra final foi composta por 2365 firmas-ano. Como metodologia estatística empregada, utilizou-se um modelo "difference in difference" com efeito fixo para empresa. O conjunto de empresas brasileiras com certificação ISO14001 compõem o grupo de tratamento, enquanto empresas que não possuem tal certificação compõe o grupo de controle.

\begin{tabular}{|c|c|c|c|c|c|c|c|c|}
\hline & \multicolumn{2}{|c|}{ Custo de Capital (WACC) } & \multicolumn{2}{|c|}{ Custo de Capital Próprio } & \multicolumn{2}{|c|}{ Custo de Capital de Terceiros } & & \\
\hline & Coef. & P-valor & Coef. & P-valor & Coef. & P-valor & & \\
\hline DID & $-0,012$ & 0,179 & $-0,001$ & $-0,109$ & 0,054 & 0,054 & & \\
\hline Primeiro Ano & 0,031 & 0,037 & 0,001 & 0,135 & 0,145 & 0,145 & & \\
\hline Beta & 0,010 & 0,131 & 0,030 & $-0,108$ & 0,007 & 0,007 & & \\
\hline Dívida CP & 0,285 & 0,000 & 0,022 & 0,193 & 0,252 & 0,252 & & \\
\hline Dívida LP & 0,326 & 0,000 & 0,010 & 0,235 & 0,142 & 0,142 & & \\
\hline ROA & $-0,223$ & 0,000 & $-0,005$ & $-0,378$ & 0,048 & 0,048 & & \\
\hline Liquidez & 0,030 & 0,000 & 0,002 & 0,135 & 0,000 & 0,000 & & \\
\hline Tangibilidade & 0,074 & 0,003 & 0,009 & $-0,562$ & 0,000 & 0,000 & & \\
\hline Tamanho & $-0,028$ & 0,000 & $-0,001$ & $-0,048$ & 0,054 & 0,054 & & \\
\hline N. Observações & 2365 & & 2365 & & 2365 & & & \\
\hline \multicolumn{9}{|c|}{ Painel B: Efeito da certificação ISO14001 no nível de endividamento e risco. } \\
\hline & \multicolumn{2}{|c|}{ Dívida Total } & \multicolumn{2}{|c|}{ Dívida CP } & \multicolumn{2}{|c|}{ Risco (Beta) } & \multicolumn{2}{|c|}{ Risco (Beta) } \\
\hline & Coef. & P-valor & Coef. & P-valor & Coef. & P-valor & Coef. & P-valor \\
\hline DID & 0,000 & 0,979 & $-0,018$ & 0,026 & 0,018 & 0,037 & $-0,031$ & 0,221 \\
\hline Primeiro Ano & $-0,001$ & 0,930 & 0,025 & 0,068 & $-0,026$ & 0,070 & 0,045 & 0,278 \\
\hline Custo Cap. Terc. & 0,005 & 0,155 & 0,001 & 0,697 & 0,004 & 0,294 & $-0,027$ & 0,005 \\
\hline Custo Cap. Próp. & 0,671 & 0,000 & 0,671 & 0,000 & 0,000 & 0,999 & 11,261 & 0,000 \\
\hline Dívida CP & & & & & & & $-0,711$ & 0,000 \\
\hline
\end{tabular}




\begin{tabular}{|c|c|c|c|c|c|c|c|c|}
\hline Dívida LP & & & & & & & $-0,317$ & 0,000 \\
\hline Beta & $-0,058$ & 0,000 & $-0,059$ & 0,000 & 0,001 & 0,929 & & \\
\hline ROA & $-0,392$ & 0,000 & $-0,145$ & 0,000 & $-0,247$ & 0,000 & 0,037 & 0,667 \\
\hline Liquidez & $-0,131$ & 0,000 & $-0,087$ & 0,000 & $-0,044$ & 0,000 & $-0,113$ & 0,000 \\
\hline Tangibilidade & $-0,392$ & 0,000 & $-0,402$ & 0,000 & 0,010 & 0,633 & $-0,385$ & 0,000 \\
\hline Tamanho & 0,053 & 0,000 & 0,001 & 0,744 & 0,051 & 0,000 & 0,015 & 0,173 \\
\hline N. Observações & 2365 & & 2365 & & 2365 & & 2365 & \\
\hline
\end{tabular}

Fonte: Elaborado pelos autores.

A estimativa do coeficiente da variável DID, o qual representa o efeito da certificação nos respectivos custos de capitais, foi significativa apenas na terceira especificação, a qual considera o custo de capital de terceiros. Especificamente, o resultado do Painel A da Tabela 3 sugere que após a certificação empresas certificadas presenciaram uma redução significativa no custo de capital de terceiros.

Assim como no estudo de Heal (2005), que avalia a relação entre RSC e custo de capital, tal redução no custo de capital de terceiros pode estar associada ao fato que as firmas passam a estabelecer relações mais sinérgicas com seus stakeholders quando enfrentam processos que aumentam a responsabilidade ambiental. Na mesma linha, o estudo de El Ghoul et al. (2011) sugere que essas influencias no custo do capital de terceiros podem ser explicadas por uma redução na assimetria de informações, o que reduz custos de monitoramento e financiamento.

Todavia, os coeficientes da dummy de Primeiro ano expostos no Painel A da Tabela 3 indicam que essa redução no custo de capital não se deu no primeiro ano em que a empresa recebe a certificação, mas sim nos anos subsequentes. $O$ resultado no primeiro ano, pelo contrário, indicam que as empresas experimentam um aumento no custo de capital no ano de certificação. Tal resultado pode ter justificativa no fato de que a implementação de estratégias ambientais apenas com o tempo pode reduzir custos ligados à gestão de desastres ambientais impostos por um regulador (Weber, 2012). Além disso, consequências como a alteração de portfólios de produtos ou lançamento de novos processos organizacionais com vistas à redução de impactos no meio ambiente pode levar um tempo até que sejam implementadas e percebidas pelo mercado (Darnall \& Edwards, 2006; Weinhofer \& Hoffmann, 2010; Martín-de Castro et al., 2015; Lee et al., 2015).

Os resultados expostos na Tabela 3 vão de encontro aos resultados de Erragragui (2017), o qual evidencia que preocupações socioambientais aumentam o custo da dívida das empresas. É importante acrescentar, entretanto, que dados socioambientais são mais abrangentes que análises que envolvem o processo de certificação ISO14001. Especificamente, o presente estudo trás análise voltada para a interface ambiental, apresentando evidências de que a certificação por meio de sistemas de gerenciamento ambiental, como é o caso do ISO14001, podem reduzir o custo de capital de terceiros das empresas no longo prazo (o que de certa forma suporta a hipótese 1), a despeito do aumento do custo de capital no ano de implantação do sistema de gerenciamento ambiental.

Os achados também vão de desencontro com Clarkson et al. (2013), cujos resultados não encontraram relação com divulgação ambiental e custo do capital. Especificamente, tais autores encontraram evidências de que informações ambientais voluntárias credíveis são de valia para a imagem das empresas, embora não expliquem significativamente variações do custo de capital. Entretanto, as análises de tal estudo foram restritas à divulgações ambientais voluntárias sobre lançamentos tóxicos por parte das empresas, e não à sinalizações associadas à adoção de sistemas de gerenciamento ambiental, como é o caso da certificação ISO14001. Os resultados do presente estudo, por outro lado, sustentam a hipótese 
de a certificação ISO14001 pode reduzir o custo de capital de terceiros das empresas no longo prazo, a despeito do aumento do custo de capital no ano de implantação do sistema de gerenciamento ambiental.

\subsubsection{Efeito da certificação no Risco}

Sobre a interface do risco, o Painel B da Tabela 3 apresenta os resultados do modelo 2 considerando-se o beta do CAPM como variável dependente e proxy para risco da empresa. Tal modelo foi utilizado para se testar a Hipótese 2, sob a qual espera-se que a sinalização ambiental, por meio da certificação ISO 14001, reduza o risco sistêmico das empresas.

Os resultados do Painél B da Tabela 3 mostram que os coeficientes das variáveis DID e Primeiro Ano não foram significativos. Tais resultados sugerem que, embora a adoção de sistemas de gerenciamento ambiental, como é o caso da certificação ISO14001, reduzirem o custo de capital de terceiros, o mesmo efeito não é observado para o nível de exposição a mercado das empresas em relação a riscos sistêmicos.

Tal resultado vai de encontro com evidências apresentadas por Sharfman e Fernando (2008), as quais mostram haver uma tendência de redução de riscos em empresas americanas associados a um menor número de ocorrências prejudiciais ao meio ambiente, multas e custos de conformidade. Song et al. (2017), na mesma linha, mostram que o comportamento ambiental responsável em empresas chinesas reduziu o risco comercial através de melhores relações com as autoridades reguladoras e consumidores.

Embora a certificação ISO14001 possa estar reduzindo riscos de conformidade e ambientais, além de tornarem essas empresas mais confiáveis sobre a perspectiva dos stakeholders (Heras-Saizarbitoria et al., 2011), o alcance da certificação parece estar limitado à fatores idiossincráticos e de discricionariedade das empresas, não necessariamente mitigando riscos sistêmicos. Nesse caso, as evidências a partir da certificação ISO14001 por parte das firmas brasileiras não suportam a hipótese 2 de que a adoção de sistemas de gestão ambiental, como é o caso da ISO14001, reduzem o risco sistêmico das empresas.

\subsubsection{Efeito da certificação no Endividamento}

O Painel B da Tabela 3 apresenta também os resultados do modelo 3 considerando-se especificações que levam em conta o endividamento total, dívida de curto prazo e dívida de longo prazo como variáveis a serem explicadas. Tais especificações foram utilizadas para se testar a Hipótese 3 na qual é analisada a interferência da sinalização ambiental, por meio da certificação ISO 14001, no montante de dívida da empresa.

Os resultados do Painel B da Tabela 3 sugerem que embora a certificação ISO14001 pareça não alterar de forma significativa o endividamento total das empresas certificadas (coeficientes das variáveis DID e Primeiro Ano não são significativos para a especificação que considera Dívida Total como variável dependente), a certificação altera a composição da dívida dessas empresas. Especificamente, observa-se em um primeiro momento uma redução na dívida de longo prazo $(-0,026)$ e um aumento da dívida de curto prazo $(0,025)$. Tais resultados podem estar sendo explicados pelos custos de implementação de processos associados à obtenção da certificação, os quais podem estar aumentando despesas das empresas no curto prazo.

Em anos posteriores à certificação, entretanto, os resultados sugerem haver de forma significativa um decréscimo da dívida de curto prazo e um aumento da dívida de longo prazo, a qual na média tem custos menores que dívidas de curto prazo (Funchal \& Monte-Mor, 2016). Tais resultados seguem alinha- 
dos a outras evidências que indicam que a certificação ISO14001 permite às empresas aumentar a sua rentabilidade por meio do aumento da vantagem competitiva, redução dos custos e despesas, e maior receita a partir de uma maior aceitação dos produtos da empresa por parte dos consumidores (Bansal \& Roth, 2002; Christmann, 2000; Harrington \& Knight, 2001). Tal melhora operacional pode influenciar o processo de obtenção de financiamentos, principalmente em mercados com restrição de acesso ao crédito, como é o caso do Brasil (Funchal \& Monte-Mor, 2016).

Diante do exposto e por meio dos resultados encontrados no Painel B da Tabela 3, não se pode rejeitar também a H3. Especificamente para a amostra brasileira estudada, a sinalização interfere na alocação da dívida da empresa, principalmente com relação a sua distribuição no tempo. Em outras palavras, a certificação parece aumentar (reduzir) a dívida de curto prazo (longo prazo) em um primeiro momento, mas reduzi-la (aumenta-la) em um momento posterior. Tais resultados são consistentes com evidências apresentadas por Cellier e Chollet (2016) e Barros, Silva e Voese (2015), nas quais bons padrões de RSC estão associados a menores custos de dívida.

Tais resultados seguem alinhados também à Song et al. (2017), sugerindo que no ano da certificação as empresas precisam arcar com custos extras para se adequarem ao novo padrão estabelecido. Tais investimentos tendem a aumentar a dívida de curto prazo, aumentando inicialmente o custo de capital. Entretanto, no decorrer dos anos, a readequação da empresa aos padrões ISO14001 passa a se associar à redução no custo de capital de terceiros, aumento da dívida de longo prazo e redução da dívida de curto prazo. Com relação a essa melhora na distribuição da dívida após a certificação ambiental, este documento gera implicações importantes para contribuir na tomada de decisão dos gestores que se esforçam para manter a empresa com boa condição econômica e financeira, com condições de dívida com menor custo de capital e prazos mais extensos para quitação (Sun \& Cui, 2014).

\subsubsection{Análise de Sensibilidade}

Embora a estimação do modelo "difference in difference" com efeito fixo para empresa tenha o intuito de mensurar em média o efeito da obtenção da certificação ISO14001 na estrutura de capital a partir da eliminação de características fixas no tempo e mediante comparação de empresas certificadas com empresas não certificadas, verifica-se que tal modelo é sensível à formação não só do grupo de tratamento, mas também à do grupo de controle, principalmente no que tange à decisão de certificação. Isso porque a decisão de certificação, por ser uma escolha endógena da firma, acaba por acrescentar ao modelo um viés de auto-seleção.

Nesse caso, faz-se necessário verificar se os resultados obtidos a partir da estimação dos modelos 1 , 2 e 3 não estão associados ao viés de auto-seleção via, por exemplo, alguns canais cujos controles não estão disponíveis, como é o caso do marketing associado ao disclosure ambiental (Wagner, 2007). Neste trabalho, especificamente, fez-se o uso do Propensity Score Matching para a obtenção de um grupo de controle mais semelhante ao grupo de tratamento sob o aspecto probabilidade de certificação ISO14001. Em outras palavras, estimou-se por meio de um logit a probabilidade das empresas se certificarem e, para cada empresa certificada (grupo de tratamento), foi obtida uma empresa sem certificação (grupo de controle), mas com probabilidade de certificação semelhante. Nesse caso, espera-se que a análise de empresas certificadas versus empresas não-certificadas, mas com probabilidades semelhantes de certificação permita uma comparação mais limpa em termos de probabilidade de certificação, mitigando-se assim questões endógenas associadas ao problema de auto-seleção. 
Em consonância com o trabalho de Shipman, Swanquist e Whited (2016), utilizou-se um caliper de 0,2 com estimação sem reposição. A partir da obtenção do grupo de controle matched, os modelos 1, 2 e 3 foram, então, estimados novamente levando-se em consideração a comparação entre empresas certificadas e não-certificadas, mas com probabilidades semelhantes de certificação. Até onde se sabe, esse é o primeiro trabalho brasileiro que lida com o viés de auto-seleção ao utilizar o Propensity Score Matching.

Os resultados reestimados dos modelos 1, 2 e 3 para a amostra matched obtida a partir do Propensity Score Matching segue apresentada nos Painéis A e B da Tabela 4. As evidências obtidas seguem alinhadas aos resultados apresentados na Tabela 3 e discutidos nas subseções anteriores. Especificamente, os resultados constantes na Tabela 4 sustentam a hipótese de que a certificação ISO14001 pode reduzir o custo de capital médio e custo de capital de terceiros das empresas no longo prazo, a despeito do aumento do custo de capital médio no ano de implantação do sistema de gerenciamento ambiental. Além disso, verifica-se que embora a certificação ISO14001 pareça não alterar de forma significativa o endividamento total das empresas certificadas, a certificação altera a composição da dívida dessas empresas na medida em que se percebe uma substituição da dívida de curto prazo por dívida de longo prazo em anos posteriores à certificação ISO14001.

De uma forma geral, embora a adoção de práticas de gerenciamento exigidas pelos padrões ISO14001 não reduza em média o risco sistêmico das empresas, percebe-se alteração na estrutura de capital das empresas brasileiras certificadas a partir da redução do custo de capital de terceiros e aumento da proporção da dívida de longo prazo.

Tabela 4: Efeito da Certificação ISO14001 no Custo de Capital, Nível de Endividamento e Risco.

Os dados abaixo se referem à estimação do efeito da certificação ISO14001 no custo de capital, nível de endividamento e risco das empresas brasileiras listadas na B3 a partir da amostra obtida utilizando-se o Propensity Score Matching. Especificamente, fez-se o uso do Propensity Score Matching em um primeiro estágio para a obtenção de um grupo de controle mais semelhante ao grupo de tratamento sob o aspecto probabilidade de certificação ISO14001. Em outras palavras, estimou-se por meio de um logit a probabilidade das empresas se certificarem e, para cada empresa certificada (grupo de tratamento), foi obtida uma empresa sem certificação (grupo de controle), mas com probabilidade de certificação semelhante. A obtenção de uma amostra matched para posterior estimação dos modelos 1, 2 e 3 teve o intuito de se mitigar possíveis problemas de auto-seleção.

\begin{tabular}{|c|c|c|c|c|c|c|c|c|}
\hline & \multicolumn{2}{|c|}{ Custo de Capital (WACC) } & \multicolumn{2}{|c|}{ Custo de Capital Próprio } & \multicolumn{2}{|c|}{ Custo de Capital de Terceiros } & & \\
\hline & Coef. & P-valor & Coef. & P-valor & Coef. & P-valor & & \\
\hline DID & $-0,018$ & 0,009 & $-0,001$ & 0,287 & $-0,125$ & 0,040 & & \\
\hline Primeiro Ano & 0,034 & 0,001 & 0,001 & 0,787 & 0,1449481 & 0,132 & & \\
\hline Beta & 0,009 & 0,136 & 0,031 & 0,000 & $-0,071$ & 0,174 & & \\
\hline Dívida CP & 0,273 & 0,000 & 0,027 & 0,000 & 0,205 & 0,376 & & \\
\hline Dívida LP & 0,309 & 0,000 & 0,012 & 0,008 & 0,414 & 0,049 & & \\
\hline ROA & $-0,285$ & 0,000 & $-0,009$ & 0,197 & $-0,666$ & 0,026 & & \\
\hline Liquidez & 0,028 & 0,000 & 0,002 & 0,045 & 0,177 & 0,000 & & \\
\hline Tangibilidade & 0,010 & 0,666 & 0,013 & 0,008 & $-0,912$ & 0,000 & & \\
\hline Tamanho & $-0,021$ & 0,000 & $-0,001$ & 0,093 & $-0,037$ & 0,249 & & \\
\hline N. Observações & 1680 & & 1680 & & 1680 & & & \\
\hline \multicolumn{9}{|c|}{ Painel B: Efeito da certificação ISO14001 no nível de endividamento e risco. } \\
\hline & \multicolumn{2}{|c|}{ Dívida Total } & \multicolumn{2}{|c|}{ Dívida CP } & \multicolumn{2}{|c|}{ Risco (Beta) } & \multicolumn{2}{|c|}{ Risco (Beta) } \\
\hline & Coef. & P-valor & Coef. & P-valor & Coef. & P-valor & Coef. & P-valor \\
\hline DID & 0,705 & 0,705 & $-0,014$ & 0,074 & 0,017 & 0,046 & $-0,024$ & 0,332 \\
\hline Primeiro Ano & 0,843 & 0,843 & 0,022 & 0,065 & $-0,025$ & 0,062 & 0,040 & 0,315 \\
\hline
\end{tabular}




\begin{tabular}{|c|l|l|l|l|l|l|l|l|}
\hline Custo Cap. Terc. & 0,103 & 0,103 & 0,000 & 0,917 & 0,006 & 0,080 & $-0,019$ & 0,084 \\
\hline Custo Cap. Próp. & 0,000 & 0,000 & 0,655 & 0,000 & 0,065 & 0,689 & 10,535 & 0,000 \\
\hline Dívida CP & & & & & & & $-0,731$ & 0,000 \\
\hline Dívida LP & & & & & & & $-0,434$ & 0,000 \\
\hline Beta & 0,000 & 0,000 & $-0,048$ & 0,000 & $-0,017$ & 0,054 & & \\
\hline ROA & 0,000 & 0,000 & $-0,249$ & 0,000 & $-0,244$ & 0,000 & 0,063 & 0,611 \\
\hline Liquidez & 0,000 & 0,000 & $-0,084$ & 0,000 & $-0,048$ & 0,000 & $-0,121$ & 0,000 \\
\hline Tangibilidade & 0,000 & 0,000 & $-0,472$ & 0,000 & $-0,024$ & 0,353 & $-0,363$ & 0,000 \\
\hline Tamanho & 0,000 & 0,000 & $-0,003$ & 0,441 & 0,052 & 0,000 & 0,012451 & 0,343 \\
\hline N. Observações & 1680 & & 1680 & & 1680 & & 1680 & \\
\hline
\end{tabular}

Fonte: Elaborado pelos autores.

\section{CONCLUSÃO}

Este estudo teve como propósito investigar especificamente o efeito da sinalização ambiental na estrutura da dívida: custo, risco e endividamento (H1, H2 e H3 respectivamente). A certificação ISO 14001 (ambiental) foi empregada como proxy de sinalização para o mercado de empresas listadas na B3 que são comprometidas com sustentabilidade.

Diante do exposto, os resultados apresentam evidências de que após a certificação ISO 14001, as empresas brasileiras negociadas na B3 obtiveram resultados qualitativamente semelhantes aos alcançados pela maioria das empresas de países desenvolvidos após também se certificarem ambientalmente. Especificamente, verifica-se redução do custo de capital total, especificamente por meio da redução do custo de capital de terceiros. Além disso, a redução no passivo circulante somada ao aumento no passivo não circulante sugere que as empresas de forma geral estão caminhando para um perfil mais sólido a longo prazo, com dívidas de maior maturidade. Tais resultados sugerem que empresas ambientalmente responsáveis que sinalizam de alguma forma suas ações ambientais tem melhor relacionamento com stakeholders, em especial credores e acionistas.

Diante do exposto e por meio dos resultados encontrados nas Tabelas 3 e 4, verifica-se que as hipóteses $\mathrm{H} 1$ e H3 são suportadas. Ou seja, para a amostra estudada, de uma forma geral, embora a adoção de práticas de gerenciamento exigidas pelos padrões ISO 14001 não reduza em média o risco sistêmico das empresas, percebe-se alteração na estrutura de capital das empresas brasileiras certificadas a partir da redução do custo de capital de terceiros e aumento da proporção da dívida de longo prazo.

Tais resultados contribuem não só de forma teórica complementando a literatura existente, como também de forma prática, para que as empresas visualizem a certificação ambiental como forma estratégica. Ou seja, se motivem a fortalecer seu gerenciamento ambiental nas operações diárias, sinalizando de forma consciente e com o mínimo de assimetria, de modo a aumentar a competitividade e promover o desenvolvimento empresarial em aspectos referentes à estrutura de capital no longo prazo.

\section{REFERÊNCIAS}

Ahmadi, A., \& Bouri, A. (2017). The relationship between financial attributes, environmental performance and environmental disclosure: Empirical investigation on French firms listed on CAC 40. Management of Environmental Quality: An International Journal, 28(4), 490-506. Doi: 10.1108/MEQ-07-2015-0132 
Albanez, T. (2015). Impact of the cost of capital on the financing decisions of Brazilian companies. International Journal of Managerial Finance, 11(3), 285-307. Doi:10.1108/JMM-02-2014-0026

Araujo, A. P., Ferreira, R. V., \& Funchal, B. (2012). The Brazilian bankruptcy law experience. Journal of Corporate Finance, 18(4), 994-1004. Doi: 10.1016/j.jcorpfin.2012.03.001

Assaf Neto, A., Guasti Lima, F., \& Procópio de Araújo, A. M. (2008). Uma proposta metodológica para o cálculo do custo de capital no Brasil. Revista de Administração-RAUSP, 43(1).

Bansal, P., \& Bogner, W. C. (2002). Deciding on ISO 14001: economics, institutions, and context. Long Range Planning, 35(3), 269-290. DOI: 10.1016/S0024-6301(02)00046-8

Barros, C. M. E., da Silva, P. Y. C., \& Voese, S. B. (2015). Relação entre o custo da dívida de financiamentos e governança corporativa no Brasil. Contabilidade, Gestão e Governança, 18(2).

Brasil. (2000). Lei n 10.165, de 27 de dezembro de 2000.

Altera a Lei no 6.938, de 31 de agosto de 1981, que dispõe sobre a Política Nacional do Meio Ambiente, seus fins e mecanismos de formulação e aplicação, e dá outras providências. Disponível em: http://www. planalto.gov.br/ccivil_03/leis/L10165.htm

Castka, P., \& Balzarova, M. A. (2018). An exploration of interventions in ISO 9001 and ISO 14001 certification context-A multiple case study approach. Journal of Cleaner Production, 174, 1642-1652. DOI: 10.1016/j.jclepro.2017.11.096

Cellier, A., \& Chollet, P. (2016). The effects of social ratings on firm value. Research in International Business and Finance, 36, 656-683. DOI: 10.1016/j.ribaf.2015.05.001

Clarkson, P. M., Fang, X., Li, Y., \& Richardson, G. (2013). The relevance of environmental disclosures: are such disclosures incrementally informative? Journal of Accounting and Public Policy, 32(5), 410-431. DOI: 10.1016/j.jaccpubpol.2013.06.008

Christmann, P. (2000). Effects of "best practices" of environmental management on cost advantage: The role of complementary assets. Academy of Management Journal, 43(4):663-680. DOI: 10.2307/1556360.

Coulson, A. B.(2009). Business Strategy \& the Environment (John Wiley \& Sons, Inc). 18(3), 149-161. DOI: $10.1002 /$ bse.584

Damodaran, A. Finanças corporativas aplicadas. Porto Alegre: Bookman, 2002.

Darnall, N., \& Edwards JR, D. (2006). Predicting the cost of environmental management system adoption: the role of capabilities, resources and ownership structure. Strategic management journal, 27(4), 301320. DOI: $10.1002 / \mathrm{smj} .518$

Dhaliwal, D., Li, O. Z., Tsang, A., \& Yang, Y. G. (2014). Corporate social responsibility disclosure and the cost of equity capital: The roles of stakeholder orientation and financial transparency. Journal of Accounting and Public Policy, 33(4), 328-355. DOI: 10.1016/j.jaccpubpol.2014.04.006

Dogui, K., Boiral, O., \& Heras-Saizarbitoria, I. (2014). Audit fees and auditor independence: The case of ISO 14001 certification. International Journal of Auditing, 18(1), 14-26. DOI: 10.1111/ijau.12008

El Ghoul, S., Guedhami, O., Kwok, C. C., \& Mishra, D. R. (2011). Does corporate social responsibility affect the cost of capital? Journal of Banking \& Finance, 35(9), 2388-2406. DOl: 10.1016/j.jbankfin.2011.02.007

Erragragui, E. (2017). Do creditors price firms' environmental, social and governance risks?. Research in International Business and Finance. 45(c) (197-207, DOI: 10.1016/j.ribaf.2017.07.151

Fernandes, S. M. (2013). Fatores que influenciam o disclosure ambiental: um estudo nas empresas brasileiras no período de 2006 a 2010. Revista Ambiente Contábil, 5(2), 250. DOI: 10.21680/2176-9036 
Ferron, R. T., Funchal, B., Nossa, V., \& Teixeira, A. J. C. (2012). Is ISO 14001 certification effective? An experimental analysis of firm profitability. BAR. Brazilian Administration Review, 9(spe), 78-94. DOI 10.1590/ S1807-76922012000500006.

Funchal, B., \& Monte-Mor, D. S. (2016). Corporate Governance and Credit Access in Brazil: The SarbanesOxley Act as a Natural Experiment. Corporate Governance: An International Review, 24(5), 528-547. DOI: 10.1111/corg.12151

Harrington, H. J. \& Knight, A. (2001). A implantação da ISO 14.000: como atualizar o sistema de gestão ambiental com eficácia. São Paulo, Atlas.

Heal, G. (2005). Corporate social responsibility: An economic and financial framework. The Geneva papers on risk and insurance-Issues and practice, 30(3), 387-409. DOI: 10.1057/palgrave.gpp.2510037

Heras-Saizarbitoria, I., Molina-Azorín, J. F., \& Dick, G. P. (2011). ISO 14001 certification and financial performance: selection-effect versus treatment-effect. Journal of Cleaner Production, 19(1), 1-12. DOI: 10.1016/j.jclepro.2010.09.002

Hermann, E. S., Reis, S. G., Ribeiro, M. S., Rezende, A. J (2009). Crédito ambiental: análise para concessão de crédito sob a ótica da responsabilidade socioambiental. BASE - Revista de Administração e Contabilidade da Unisinos 6(1):37-48, DOI: 10.4013/base.2009.61.04

Hojnik, J., Ruzzier, M., \& Antončič, B. (2017). Drivers of eco-innovation: empirical evidence from Slovenia. International Journal of Entrepreneurship and Innovation Management, 21(4-5), 422-440. DOI: 10.1504/ IJEIM.2017.085688

Jenkins, H., \& Yakovleva, N. (2006). Corporate social responsibility in the mining industry: Exploring trends in social and environmental disclosure. Journal of cleaner production, 14(3-4), 271-284. DOI: 10.1016/j. jclepro.2004.10.004

Lee, K. H., Min, B., \&Yook, K. H. (2015). The impacts of carbon (CO2) emissions and environmental research and development (R\&D) investment on firm performance. International Journal of Production Economics, 167, 1-11. DOI: 10.1016/j.jpe.2015.05.018

Lock, I., \& Seele, P. (2015). Analyzing sector-specific CSR reporting: Social and environmental disclosure to investors in the chemicals and banking and insurance industry. Corporate Social Responsibility and Environmental Management, 22(2), 113-128. DOI: 10.1002/csr.1338

Mackey, A., Mackey, T. B., \& Barney, J. B. (2007). Corporate social responsibility and firm performance: Investor preferences and corporate strategies. Academy of management review, 32(3), 817-835. DOI: 10.5465/amr.2007.25275676

Martín-de Castro, G., Amores-Salvadó, J., \& Navas-López, J. E. (2015). Environmental management systems and firm performance: improving firm environmental policy through stakeholder engagement. Corporate social responsibility and Environmental Management, 23(4), 243-256. DOI: 10.1002/csr.1377

Mahoney, Lois; Roberts, Robin W. (2007) Corporate social performance, financial performance and institutional ownership in Canadian firms. In: Accounting forum. Elsevier, 233-253. DOI: 10.1016/j.accfor.2007.05.001

Massoud, M. A., Fayad, R., Kamleh, R. \& El-Fadel, M. (2010). Environmental Management System (ISO 14001) Certification in Developing Countries: Challenges and Implementation Strategies. Environmental Science \& Technology. 44(6), 1884-1887. DOI: 10.1021/es902714u

Matuszak-Flejszman, A. (2009). Benefits of Environmental Management System in Polish Companies Compliant with ISO 14001. Polish Journal of Environmental Studies, 18(3): 411-419. 
Matuszak-Flejszman, A. Hadryjańska, B., Górna, J. (2013). Changes in environmental management after Poland's entry to the EU - the example of the dairy sector. Polish Journal of Environmental Studies, 22(3): 781-791. DOI: 10.15244/pjoes/65544

Matsumura, E. M., Prakash, R., \& Vera-Muñoz, S. C. (2013). Firm-value effects of carbon emissions and carbon disclosures. The Accounting Review, 89(2), 695-724. DOI: 10.2308/accr-50629

McGuire, W. (2014). The effect of ISO 14001 on environmental regulatory compliance in China. Ecological Economics, 105, 254-264. DOI: 10.1016/j.ecolecon.2014.06.007

Mengze, H., \& Wei, L. (2015). A Comparative Study on Environment Credit Risk Management of Commercial Banks in the Asia-Pacific Region. Business Strategy and the Environment, 24(3), 159-174. DOI: 10.1002/bse. 1810

Montabon, F., Melnyk, S. A., Sroufe, R., \& Calantone, R. J. (2000). ISO 14000: assessing its perceived impact on corporate performance. Journal of Supply Chain Management, 36(1), 4-16. DOI: 10.1111/j. 1745-493X.2000.tb00073.x

Orlitzky, M., \& Benjamin, J. D. (2001). Corporate social performance and firm risk: A meta-analytic review. Business \& Society, 40(4), 369-396. DOI: 10.1177/000765030104000402

Paulraj, A., \& De Jong, P. (2011). The effect of ISO 14001 certification announcements on stock performance. International Journal of Operations \& Production Management, 31(7), 765-788. DOI: $10.1108 / 01443571111144841$

Richardson, A. J., \& Welker, M. (2001). Social disclosure, financial disclosure and the cost of equity capital. Accounting, organizations and society, 26(7-8), 597-616. DOI: 10.1016/S0361-3682(01)00025-3

Rao, P., \& Holt, D. (2005). Do green supply chains lead to competitiveness and economic performance? International Journal of Operations \& Production Management, 25(9/10): 898. DOI: $10.1108 / 01443570510613956$

Schlischka, H. E.; REIS, S. G. D.; Ribeiro, M. S.; Rezende, A. J. (2009). Crédito ambiental: análise para concessão de crédito sob a ótica da responsabilidade socioambiental. BASE Revista de Administração e Contabilidade da UNISINOS, 6(1), 37-48. DOI: 10.4013/base.2009.61.04

Serghiescu, L., \& Văidean, V. L. (2014). Determinant factors of the capital structure of a firm-an empirical analysis. Procedia Economics and Finance, 15, 1447-1457. DOI: 10.1016/S2212-5671(14)00610-8

Sharfman, M. P., \& Fernando, C. S. (2008). Environmental risk management and the cost of capital. Strategic management journal, 29(6), 569-592. DOI: 10.1002/smj.678

Shipman, J. E., Swanquist, Q.T., \& Whited, R. L. (2016). Propensity score matching in accounting research. The Accounting Review, 92(1), 213-244. DOI: 10.2308/accr-51449

Song, H., Zhao, C., \& Zeng, J. (2017). Can environmental management improve financial performance: An empirical study of A-shares listed companies in China. Journal of cleaner production, 141, 1051-1056. DOI: 10.1016/j.jclepro.2016.09.105

Spence, M. (1973). Job Market Signalling. Quarterly Journal of Economics, 87, 355-374. DOI: $10.2307 / 1882010$

Spence, M. (2002). Signaling in Retrospect and the Informational Structure of Markets. American Economic Review, 92(3), 434-459. DOI: 10.1257/00028280260136200

Spicer, B. H. (1978). Investors, corporate social performance and information disclosure: An empirical study. Accounting Review, 53(1), 94-111. 
Stefan, A., \& Paul, L. (2008). Does it pay to be green? A systematic overview. The Academy of Management Perspectives, 22(4), 45-62. DOI: 10.5465/AMP.2008.35590353.

Sun, W., \& Cui, K. (2014). Linking corporate social responsibility to firm default risk. European Management Journal, 32(2), 275-287. DOI: 10.1016/j.emj.2013.04.003

Teixeira, E.A., Nossa, V., \& Funchal, B. (2011). O índice de sustentabilidade empresarial (ISE) e os impactos no endividamento e na percepção de risco. Revista Contabilidade \& Finanças-USP, 22(55), 29-44. DOI: 10.1590/S1519-70772011000100003.

Testa, M., \& D'Amato, A. (2017). Corporate environmental responsibility and financial performance: Does bidirectional causality work? Empirical evidence from the manufacturing industry. Social Responsibility Journal, 13(2), 221-234. DOI: 10.1108/SRJ-02-2016-0031.

To, W. M., \& Tang, M.N.F. (2014). The adoption of ISO 14001 environmental management systems in Macao SAR, China:Trend, motivations, and perceived benefits. Management of Environmental Quality: An International Journal, 25(2), 244-256. DOI: 10.1108/MEQ-01-2013-0002.

Vasi, I. B., \& King, B. G. (2012). Social movements, risk perceptions, and economic outcomes: The effect of primary and secondary stakeholder activism on firms' perceived environmental risk and financial performance. American Sociological Review, 77(4), 573-596. DOI:10.1177/0003122412448796

Wagner, M. (2007) Integration of Environmental Management with other Managerial Functions of the Firm. Empirical Effects on Drivers of Economic Performance. Long Range Planning. 40(6), 611-628. DOI: 10.1016/j.Irp.2007.08.001

Weber, Olaf. (2005). Sustainability benchmarking of European banks and financial service organizations. Corporate Social Responsibility \& Environmental Management, 12(2), 73-87. DOI: 10.1057/palgrave. gpp.2510037

Weber, O. (2012). Environmental credit risk management in banks and financial service institutions. Business Strategy and the Environment, 21(4), 248-263. DOI: 10.1002/bse.737

Weinhofer, G., Hoffmann, V. H. (2010). Mitigating climate change-how do corporate strategies differ?. Business Strategy and the Environment, 19(2), 77-89. DOI: 10.1002/bse.618

Yang, C.C., Yang, K.J., Peng, S.Y. (2011). Exploration strategies and key activities for the system of environmental management. Total Quality Management \& Business Excellence. 22(11), 1179-1194. DOI: 10.1080/14783363.2011.603201.

Zeng, S. X., Tam, C. M., Vivian, W. Y.T., \& Deng, Z. M. (2005). Towards implementation of ISO 14001 environmental management systems in selected industries in China. Journal of Cleaner Production, 13(7), 645-656. DOI: 10.1016/j.jclepro.2003.12.009

Zhu, Q., Cordeiro, J., Sarkis, J. (2013). Institutional pressures, dynamic capabilities and environmental management systems: Investigating the ISO 9000 - environmental management system implementation linkage. Journal of Environmental Management, 114, 232-242. DOI: 114: 232-242. DOI: 10.1016/j. jenvman.2012.10.006

\section{Como referenciar}

Martins, J. P.; Monte-mor, D. S.; Nossa, S. N.; Nossa, V. (2019). Responsabilidade ambiental, custo capital, risco e endividamento. Advances in Scientific and Applied Accounting, 12(2), Maio / Ago. 